\title{
Impact of inhibition in striatal decorrelation of cortical neuronal avalanches
}

\author{
Jovana J Belić ${ }^{1,2^{*}}$, Andreas Klauss ${ }^{3,4}$, Dietmar Plenz ${ }^{4}$, Jeanette Hellgren Kotaleski,3 \\ From Twenty Second Annual Computational Neuroscience Meeting: CNS*2013 \\ Paris, France. 13-18 July 2013
}

The Basal Ganglia represent subcortical structures that have a crucial role in determining when a given motor program should be selected and called into action [1]. The input region of the Basal Ganglia (the striatum) contains several distinct cell types. $90-95 \%$ of them are medium spiny projection neurons (MSNs) that have high threshold for activation and represent the sole source of the output. There is also a small population of fast-spiking interneurons (FSIs) that receive inputs from a wider range of distinct cortical regions compared to projection neurons [2]. Two sources of GABAergic inhibition onto MSNs are the feedforward inhibition via the FSIs and the feedback inhibition from the axon collaterals of the MSNs themselves. Feedforward inhibition is very powerful and may filter cortical information transmitted by striatal projection neurons [3]. In contrast, feedback inhibition between pairs of MSNs acts predominantly at the distal dendrites, but may still significantly control the overall level of activity of the spiny neurons [4].

We simultaneously recorded local field potentials (LFPs) in the cortex and striatum in order to determine how striatum processes cortical neuronal avalanches. Cortical neuronal avalanches represent activity clusters with a cluster size distribution that follows a power law with exponent -1.5 [5]. Analysis of experimental data revealed that activity clusters in striatum also follow power law distributions, but with an exponent significantly lower than what is observed in the cortex [6]. To understand what controls the LFP statistics observed in experiments, we developed an abstract model of the cortico-striatal network. We investigated to what extent the connectivity pattern between cortex and striatum as well

\footnotetext{
* Correspondence: belic@kth.se

'Computational Biology, Royal Institute of Technology (KTH), Stockholm, 10691, Sweden

Full list of author information is available at the end of the article
}

as the inhibition within striatum can explain the experimental results [7]. Our model predicts that striatal inhibition plays a prominent role in shaping the observed striatal dynamics and decorrelating the striatal responses to cortical neuronal avalanches. To understand the contribution of feedforward vs feedback inhibition to the dynamics, we extended our abstract model to spiking networks. We used the model to quantify the role of feedback and feedforward inhibition for decorrelating MSNs, and preliminary results suggest that FSIs play a significant role.

\section{Author details}

${ }^{1}$ Computational Biology, Royal Institute of Technology (KTH), Stockholm, 10691, Sweden. ${ }^{2}$ Bernstein Center Freiburg, University of Freiburg, Freiburg, 79104, Germany. ${ }^{3}$ Department of Neuroscience, Karolinska Institutet (KI), Stockholm, 17177, Sweden. ${ }^{4}$ Section of Critical Brain Dynamics, National Institute of Mental Health (NIH), Bethesda, USA.

Published: 8 July 2013

\section{References}

1. Grillner S, Hellgren Kotaleski J, Menard A, Saitoh K, Wikström M: Mechanisms for selection of basic motor programs-roles for the striatum and pallidum. Trends in Neuroscience 2005, 28:364-370.

2. Ramanathan J, Hanley JJ, Deniau JM, Bolam JP: Synaptic convergence of motor and somatosensory cortical afferents onto GABAergic interneurons in the rat striatum. Journal of Neuroscience 2002, 22:8158-8169.

3. Mallet N, Moine K, Charpier S, Gonon F: Feedforward Inhibition of Projection Neurons by Fast-Spiking GABA Interneurons in the Rat Striatum In Vivo. The Journal of Neuroscience 2005, 25:3857-3869.

4. Wickens J, Arbuthnott G, Shindou T: Simulation of GABA function in the basal ganglia: computational models of GABAergic mechanisms in basal ganglia function. Progress in Brain Research 2007, 160:313-329.

5. Beggs J, Plenz D: Neural avalanches in neocortical circuits. The Journal of Neuroscience 2003, 23:11167-11177.

6. Klaus A, Plenz D: Striatal processing of cortical neuronal avalanches. New Orleans, LA: Society for Neuroscience; 2012.

7. Belić J, Klaus A, Plenz D, Hellgren Kotaleski J: Neuronal avalanches and the cortico-striatal network. BMC Neuroscience 2012, 13(Suppl1):P122.
C Biomed Central

C 2013 Belićć et al; licensee BioMed Central Ltd. This is an Open Access article distributed under the terms of the Creative Commons Attribution License (http://creativecommons.org/licenses/by/2.0), which permits unrestricted use, distribution, and reproduction in any medium, provided the original work is properly cited. 
doi:10.1186/1471-2202-14-S1-P165

Cite this article as: Belić et al: Impact of inhibition in striatal

decorrelation of cortical neuronal avalanches. BMC Neuroscience 2013

14(Suppl 1):P165.

Submit your next manuscript to BioMed Central and take full advantage of:

- Convenient online submission

- Thorough peer review

- No space constraints or color figure charges

- Immediate publication on acceptance

- Inclusion in PubMed, CAS, Scopus and Google Scholar

- Research which is freely available for redistribution

Submit your manuscript at 